\title{
Increasing the efficiency of teaching Russian as a foreign language in the context of distance learning
}

\author{
Olga Nikolaevna Altukhova', Galina Vasilevna Vorobeva $^{2}$, Arvid Ronaldovich \\ Ingemansson $^{2}$, Elena Aleksandrovna Ptitsyna ${ }^{21}$, and Elena Vladimirovna Tiumentseva ${ }^{2}$ \\ ${ }^{1}$ Volgograd State Medical University, Department of the Russian Language and Socio-Cultural \\ Adaptation, Volgograd, Russia \\ ${ }^{2}$ Volgograd State Technical University, Pre-University Training Faculty, Volgograd, Russia
}

\begin{abstract}
The article considers topical issues of organizing distance learning of teaching Russian as a foreign language at university in the context of the global COVID-19 pandemic. The purpose of the study, based on the practice of working with foreign citizens, was to analyze the efficiency of university training of foreigners in Russian using Internet technologies. The work focuses on the importance and feasibility of using modern methods of teaching Russian as a foreign language to achieve optimal results of the educational process. Methodologically, the study is based on the basic principles and provisions of the systemic and structural-functional approaches. The authors of the article note that, contrary to the prevailing stereotype, distance learning is a rather promising form of organizing the educational process with a number of positive aspects. It contributes to the successful solution of basic pedagogical tasks, allowing foreign students to form both linguistic and professional competence in Russian universities. The article concludes that in modern conditions, Russian as foreign language teachers should constantly improve their level of technical literacy, choosing from a significant number of opportunities provided by the worldwide network, optimal for achieving the educational tasks set in a specific situation. Besides, the successful organization of the distance learning process is not possible without a fundamental rethinking of methodological guidelines and techniques used by a teacher. According to the authors, special attention is paid to methods of productive influence on the educational motivation of foreign students. Such balanced approach guarantees high efficiency of the distance educational process in teaching Russian as a foreign language.
\end{abstract}

Keywords: distance education, foreign students, information technologies

\section{Introduction}

\footnotetext{
${ }^{1}$ Corresponding author: geeterra@mail.ru
} 
The epidemiological situation in Russia during the global COVID-19 pandemic affected the entire education system and forced universities to switch to complete distance learning. "Distance learning is a form of education in which the interaction between teachers and between students themselves is carried out at a distance" [1]. In the changed conditions of academic activity, an urgent need arose to rethink the traditional approaches to organizing the process of teaching Russian as a foreign language, which determines the relevance of this study. The scientific novelty of such works lies in the generalization of teaching staff experience in the professional training of foreign citizens at Russian universities through distance learning.

The theoretical understanding of a complex phenomenon of online training of foreigners was addressed in the works by such recognized RFL experts and the theory and practice of distance learning as E.S. Polat [1], I.I. Baranova, M.V. Vinogradova, M.Yu. Dotsenko T.P. Zaichenko [2]. The distance method of organizing the educational process has obvious disadvantages and undeniable strengths as well, which forces linguists to improve their technical and pedagogical skills, based on the realities of the current situation.

The purpose of the article is to analyze the efficiency of university training of foreigners in Russian in the context of distance communication between students and teachers to improve the quality of students' universal and professional competencies, to present the possibilities of using modern methods of teaching Russian as a foreign language (RFL) in philologists' practice. Achievement of this purpose required the solution of several specific tasks, for example, to show the need for competent use of the capabilities of information and computer technologies to create a full-fledged educational environment; to outline methodically effective techniques for increasing students' educational motivation, developing the skills of independent work in the distance learning mode.

\section{Methods}

The methodological basis of the study is formed by the principles and provisions of the systemic and structural-functional approaches.

\section{$3 \quad$ Results and discussion}

With the transition of the educational process to the online environment, the question arose not only about ensuring the continuity of the educational process, but also about its efficiency, which directly depends on various factors, primarily on the readiness of university teachers for this form of education, the availability of necessary technical means for the feedback of teachers with students, the existence of appropriate educational resources. RFL teachers were forced to quickly adapt to the new distance learning mode and significantly revise training forms, methods and techniques in order to maintain the quality of teaching at the required level and to form foreign students' foreign language literacy and communicative competencies necessary for their successful social-cultural and professional communication in Russian in the future.

Distance learning as a type of interactive communication is intended "for professional training and retraining using advanced information technologies" [3]. Undoubtedly, the Internet has a significant potential for learning opportunities, contributing to the maximum approximation of the distance environment to the traditional training conditions, "which effectively helps to achieve educational goals in the process of continuous interaction between teachers and students and between students themselves when performing diverse communication tasks online" [4]. In distance learning, one of the main tasks of a modern teacher is the selection and use of the most effective information teaching aids [5-7]. 
RFL teachers should have digital literacy and be able to apply modern information and communication technologies (ICT) in linguodidactic activities, which are becoming an integral part of distance learning. In the context of language education, they have the ability to create a unified technological learning language environment and are able to form in foreign students all the necessary communicative, general professional and professional competencies, as well as cognitive skills to search and analyze information and apply Internet technologies for self-education. "The use of digital information resources in teaching is becoming the most important feature of optimization of the educational process at modern universities" [8]. For the organization of distance learning, various technological platforms, information and educational environments, various software resources and telecommunication types can be used.

The Internet provides foreign students with the possibility of real communication in the target language, access to authentic educational and methodological materials (electronic textbooks, manuals, presentations, reference books and encyclopedias) and a huge number of educational resources in text, audio and video formats. Also, the university electronic information educational environment (EIEE) allows uploading an unlimited amount of original educational content (text and multimedia training materials), as well as tasks for current and intermediate certification. Modern information and communication technologies allow teachers to effectively organize the learning process so that students study actively and with interest, see the results of their activities, learn to work independently, i.e. in this case, one can talk about the motivating function of ICT in the educational process [9-11].

Distance learning requires the use of various Internet platforms that provide all the necessary types of communication for participants in the educational process - teachers and students (video communication, voice communication, text messaging, sending audio messages and files), which helps to make the process of teaching Russian as a foreign language as efficient as possible and close to the usual traditional form (classroom training). Zoom and Skype platforms are the most convenient for studying; they allow organizing productive educational activities of foreign students (individual or group activities) in the online mode using video communication (synchronous learning). Making conference calls with a large number of participants creates the necessary "effect" of the presence of all participants in the educational process at an offline lesson in a classroom environment. Two-way "teacher-student" communication allows the teacher to control all developed speech skills and abilities of foreign students, as well as the degree of understanding of the studied subject, which increases the efficiency of teaching Russian. Zoom and Skype platforms also allow students to demonstrate a variety of multimedia resources (presentations made in Microsoft PowerPoint, EduGlogster, Prezi, Twitter, audio and video presentations), text educational material in the form of Word and Pdf files. They have chats to exchange messages, to transfer audio and video files.

It is also advisable for teachers to use network technologies for an asynchronous mode of teaching Russian as a foreign language, for example, the use of the Moodle platform for testing, various messengers (WhatsApp, Viber, Telegram, Facebook, etc.) to create group chats to coordinate the work of groups, send assignments, links to necessary materials, to edit students' written assignments.

Electronic communication is an effective language practice. "Modern computer technologies provide new opportunities in organizing practical sessions and independent work of students, and make it possible to improve the system for assessing the results of mastering the discipline" [12]. Digital tools activate the educational process, use various channels of students' perception, increase their level of motivation. Information and communication technologies are focused on empowering international students. "Modern 
higher professional education should guarantee a future specialist the successful adaptation to conditions of professional activity" [13].

Distance learning, the impossibility of full immersion in the language environment, the lack of constant contact with native speakers, the psychological isolation of students not only make specialists pay close attention to the technical aspect of distance communication with students, but also help to rethink in many ways the traditional methodology of teaching the discipline that has developed over the years. In particular, it seems necessary to pay special attention to systemic repetition, consolidation of language material, starting from the very first steps of its mastery. As mentioned above, distance learning assumes a variety of forms of technical communication with students: from communication through various video communication services to thematic correspondence in chats. According to the authors' observations, the efficiency of language learning increases when a particular topic is presented sequentially in several different ways. Thus, when learning the Russian case system, studying the meanings of cases, it is advisable to discuss grammatical material in an online lesson and then fix it in the chat, duplicating the theory and completing a number of tasks of different levels of complexity. Home reading texts, audio and video materials sent to students should also contain a high percentage of appropriate grammatical structures.

The concentric system of presentation and distribution of lexical and grammatical material, generally somewhat slowing down the pace of learning, in a situation of distance communication between a teacher and foreign students is a fundamentally important approach. Multiple repetitions of what was previously studied with the subsequent gradual expansion of the coverage of related linguistic forms allows deeply penetrating into the essence of the studied phenomena.

Long-term observations of distance learning Russian as a foreign language during the pandemic suggest that the level of students' educational has decreased. The obvious prerequisites for this phenomenon are a number of objective factors. In addition to being isolated from the Russian-speaking environment, foreign students found themselves in almost complete isolation from the educational team, from the psychologically comfortable extracurricular communication with groupmates. The inability to clearly make plans for the future, the lack of lively, emotionally positive communication in Russian and the atmosphere of student community necessary for social interaction - all this leads to a decrease in the desire to learn, to a pessimistic assessment of prospects for the personal cognitive activity. "A student with a low level of motivation is not able to develop the competencies he/she needs as a professional in the chosen field of study" [14]. The lack of direct contact with the teacher in the educational process also creates a certain obstacle. Researchers note that "a teacher's role in the process of their adaptation to the conditions of the new academic and socio-cultural environment is certainly important for foreign students. Direct communication with the teacher helps to eliminate psychological barriers, emotionally lighten the situation and increase educational motivation" [2].

Moreover, the objective difficulty of the Russian language for perception, the need to analyze and master complex linguistic phenomena even at an elementary level of education often make students doubt their own strengths and desire to continue studies. Obviously, when mastering the phonetic, lexical, grammatical aspects of the Russian language, a strict systematic approach is needed; missing classes at one of the stages causes difficulties when working at a higher level.

The current difficult situation in the field of economics has led to a significant increase in the number of working students, which also negatively affects class attendance, academic performance and cognitive motivation among students.

To positively influence the degree of foreign students' interest in the academic discipline, it is necessary to make the course more advanced, interesting, pragmatic: to use 
examples-illustrations that are thematically relevant to young people, introduce a cultural component in classes by telling about Russia, its history, culture, nature, cities, sights, traditions. The close connection of the studied grammatical material with speaking practice will also be in demand, when phrases often used in everyday life are given to students for the analysis, reproduction and memorization.

The widespread use of capabilities of the global network also seems to be very effective. In distance learning the student does not have any difficulties with viewing and listening to the content recommended by the teacher: additional video lessons on RFL, presented in free access, songs in Russian, films, animation. It will increase the educational motivation and constant desire of a specialist teacher to create situations of success for students in which they can see their language learning progress, get a detailed assessment of their achievements $[15,16]$. Also, systematic work on creating a full-fledged educational team in a group where students will be able to communicate in Russian, evaluate each other, exchange comments, advice, wishes and strive not to lag behind their groupmates, reaching a new level of training together, will help to stimulate cognitive motivation.

\section{Conclusion}

Summarizing the above, it can be concluded that distance learning is a rather promising form of study, and the correct organization of the educational process when teaching Russian as a foreign language in an online environment allows students to develop all the communication and speech skills and abilities required for mastering the Russian language, as well as to form all necessary universal, general professional and professional competences, i.e. contributes to the successful achievement of pedagogical objectives and the effective implementation of all learning-related goals.

Speaking about the prospects of distance learning of the Russian language at university, it should be noted that in order to switch to complete online education, teachers need not only to have extensive experience in the digital educational environment, but also to rethink the search for technical teaching aids, modify the methodological basis and learn to combine technical capabilities with methodological literacy.

\section{References}

1. E.S. Polat, Teoriya i praktika distantsionnogo obucheniya [Theory and practice of distance learning] (Academy Publishing Center, Moscow, 2004)

2. I.I. Baranova, M.V. Vinogradova, M.Yu. Dotsenko, Prosp. Sci. and Edu. 6(48), 204-219 (2020). https://doi.org/10.32744/pse.2020.6.16

3. A.A. Beloglazov, L.B. Beloglazova, V.V. Mokashov, P.A. Kopylova, RUDN Bul. Ser.: Edu. Inf. 15(1), 38-45 (2018). https://doi.org/10.22363/2312-8631-2018-15-1-38-45

4. N.Yu. Bychkovskaya, Innov. Sci. Edu. 25, 513-517 (2021)

5. V.P. Smorchkova, V.V. Tarakanova, Munic. Edu.: Innov. and Exp. 4, 14-19 (2018)

6. D.V. Gramma, I.V. Shukurova, Sci. and Pedag. Rev. 3(25), 151-157 (2019). https://doi.org/10.23951/2307-6127-2019-3-151-157

7. E.A. Romanova, M.A. Volkova, B. Li, Prosp. Sci. and Edu. 1(49), 276-288 (2021). https://doi.org/10.32744/pse.2021.1.19

8. S. Shitov, Norw. J. Devel. Int. Sci. 43(3), 62-64 (2020)

9. E. Ekmekçi, Procedia - Soc. and Behav. Sci. 176 (2015). https://doi.org/10.1016/j.sbspro.2015.01.487 
10. Y. Moroz, T. Gordienko, V. Hrabrova, O. Medvedeva, Amazonia Investiga, 8(22), 280-285 (2019)

11. R.S. Jansen, A. van Leeuwen, J. Janssen, R. Conijn, L. Kester, Comp. \& Edu. 146 (2020). https://doi.org/10.1016/j.compedu.2019.10377

12. I.E. Korotaeva, Mod. Sci. 4, 101-107 (2020)

13. D.I. Novoseletskaya, Prob. Mod. Pedag. Edu. 67(3), 128-131 (2020)

14. T.A. Tantsura, World Sci., Cult., Edu. 3(82), 281-282 (2020)

15. V.E. Melnikov, Bul. Novgorod State Univ. 5(96), 61-64 (2016)

16. S.E. Nadkha, A.M. Maslova, E.O. Kuzmina, Philol. Sci. Iss. Theory and Prac. 13(1), 335-340 (2020). https://doi.org/10.30853/filnauki.2020.1.67 